\title{
Formability and Sinterability of Hydrothermally Crystallized Monodispersed Titanium Dioxide Particles
}

\author{
Masao KONDO, Hiroshi FUNAKUBO, Kazuo SHINOZAKI and Nobuyasu MIZUTANI \\ Department of Inorganic Materials, Faculty of Engineering, Tokyo Institute of Technology, 2-12-1, O-okayama, Meguro-ku, Tokyo \\ 水熱法により結晶化した単分散酸化チタン微粒子の成形性及び焼結性 \\ 近藤正雄・舟窪 浩・篠㟝和夫・水谷惟恭 \\ 東京工業大学工学部無機材料工学科, 152 東京都目黒区大岡山 2-12-1
}

152

[Received October 31, 1994; Accepted February 21, 1995]

\begin{abstract}
New forming process of nano-sized particles without a binder was proposed. Compacts of spherical amorphous agglomerated monodispersed titanium dioxide particles $(\sim 0.7 \mu \mathrm{m})$ synthesized by the alkoxide method were hydrothermally treated in an autoclave to crystallize the primary particles $(\sim 13 \mathrm{~nm})$ to anatase single crystal. The hydrothermally treated compacts were compressed by cold isostatic press (CIP) and the hydrothermally treated particles were crushed to many nano-sized anatase particles to form again dense green bodies (61\%) without a binder by CIP. The high formability of nano-sized anatase particles is considered to result in the agglomerated structure of hydrothermally treated particles. Green compacts obtained by this process showed high sinterability. Dense rutile bodies ( $99 \%$ of the theoretical density) were obtained by sintering at $900^{\circ} \mathrm{C}$ for $24 \mathrm{~h}$.
\end{abstract}

Key-words : Titanium dioxide, Monodispersed particle, Hydrothermal treatment, Cold isostatic press and sintering, Nano-sized particle

\section{Introduction}

Nano-sized ceramic particles are noted as sinterable raw materials at a low temperature or for a short heating time. The sintered body consisting of nanosized particles is also expected as nano-composite materials.1),2) Low-temperature sintering prevents grains from growing abnormally and gives a sintered body with a uniform and fine microstructure.

Today, to improve formability of a powder, many granulate processes such as addition of a binder and a spray dry process are used. ${ }^{3)}$ However, these processes have some problems in the forming of nano-sized particles. Usually, nano-sized particles agglomerate strongly to form submicron secondary particles. When the nano-sized particles granulate by spray dry process, the granules form the tertiary particles of them. When the tertiary particles are packed, the secondary particles are only rearranged and primary nano-sized particles are not rearranged by forming due to the strong agglomeration. Hence, the density of the green body does not increase. In addition process of a binder, a large amount of a binder is needed to cover a high surface area of nano-sized particles. Since the ratio on the mass of a binder and of particles increases with decrease of the particle size, the green density is low after the burning of the binder. A good process to improve formability of nanosized particles also have not been established yet.

Monodispersed titanium dioxide particles synthesized by alkoxide methods ${ }^{4), 5)}$ changed from amorphous state into anatase particles by hydrothermal treatment.6),7) These powders consisting of agglomeration of the nano-sized particles were crushed by ultrasonic treatment, indicating that the attractive forces between the nano-sized particles are weak. We expect that it is easy to crush their agglomerated structure of the hydrothermally treated monodispersed titanium dioxide particle by cold isostatic press (CIP) and to pack those primary particles densely. In this study, a new forming process of the nano-sized anatase particles without a binder was proposed. The purpose of this study is to clarify the packing behavior and sinterability of the hydrothermally treated monodispersed titanium dioxide particles.

\section{Experimental}

Monodispersed titanium dioxide particles were synthesized by Ikemoto et al. method. $\left.{ }^{5}\right)$ As-prepared powders were amorphous and the average diameter is $0.7 \mu \mathrm{m}$. As-prepared powder was dried at $60^{\circ} \mathrm{C}$ for $12 \mathrm{~h}$ after washing in ethanol. The dried powder was ground to preform into the compact by die pressing with $29 \mathrm{MPa}$. The powder kept their shape after this preforming process. The sizes of these compacts were from 10 to $15 \mathrm{~mm} \phi$ in diameter and $<3 \mathrm{~mm}$ in thickness. These compacts were hydrothermally treated in an autoclave at $250^{\circ} \mathrm{C}$ under a pressure of $4 \mathrm{MPa}$ for $1 \mathrm{~h}$. Many nano-sized particles were produced in the hydrothermally treated powder (hereafter called $\mathrm{H}$-powder). It was difficult to form these nano-sized particles with die pressing due to lamination. So, the compacts were dried to compress by CIP under a pressure below $392 \mathrm{MPa}$ without a binder before sintering by electric furnace. The heating rate was $240^{\circ} \mathrm{C} \cdot \mathrm{h}^{-1}$. The isothermal sintering 
was run by quick insert of the green bodies into a furnace. To compare the forming behavior of the produced nano-sized particles, a commercial anatase powder (average size $30 \mathrm{~nm}$ ) was preformed into compacts by die pressing with $29 \mathrm{MPa}$ with same condition.

The H-powder was cut by microtome (ReichertNissei, FC4E) to observe the internal microstructure, after solidification of a resin. The microstructures of the nano-sized particles were observed with a transmission electron microscope (TEM ; JEM200CX, JEOL) after the slurry of particles dispersed in isopropanol was dropped onto a copper mesh coated with monolayer. The phases were determined by X-ray diffraction (XRD ; PW-1700, Philips). The microstructures of green and sintered bodies were observed by scanning electron microscopes (SEM ; JSM-T200 and FE-SEM, JSM-890S, JEOL). The SEM samples were fixed by carbon tape on a brass holder and a gold thin film was coated on the surface of specimen. The pore size distributions of the green bodies were measured with a mercury porosimeter. The minimum detectable pore size of this apparatus was $6 \mathrm{~nm}$. The densities of green and sintered bodies were determined by measurement of sizes and weight or by the Archimedes method, respectively. As the theoretical density for anatase and rutile, 3.89 and $4.26 \mathrm{~g} \cdot \mathrm{cm}^{-3}$ were used, respectively.

\section{Results and discussion}

\subsection{Packing behavior}

Figure 1 shows the microstructures of $\mathrm{H}$-powder treated at $250^{\circ} \mathrm{C}$ for $1 \mathrm{~h}$ (Fig. 1 (A)), of primary particles crushed by ultrasonic treatment (Fig. 1(B)) and of a commercial powder (Fig. 1(C)). Many nano-sized particles were produced by the hydrothermal treatment in H-powder. The internal microstructure was uniform (Fig. 1(A)). H-powder was crushed by ultrasonic treatment and highly dispersed in isopropanol (Fig. 1(B)). The average size of these particles with a narrow size distribution ${ }^{7)}$ is $13 \mathrm{~nm}$. Since these particles are agglomerated by weak attractive forces, rearrangement of the particles is expected in forming and early sintering process. The agglomeration of the commercial powder was not crushed by ultrasonic treatment, although their size is larger than that of the produced nano-sized particles (Fig. 1(C)).

Figure 2 shows the XRD patterns of the powder before and after hydrothermal treatment at $250^{\circ} \mathrm{C}$ for $1 \mathrm{~h}$. As-prepared powder was amorphous and crystallized into anatase by hydrothermal treatment. In previous paper, we reported that the produced nano-sized particles were anatase single crystals. ${ }^{7}$ Therefore, these particles are considered to show a high disperse ability as shown in Fig. 1(B).

Figure 3 shows change of the relative density of the green compact of $\mathrm{H}$-powder and the commercial powder with the CIP pressure. The green density of
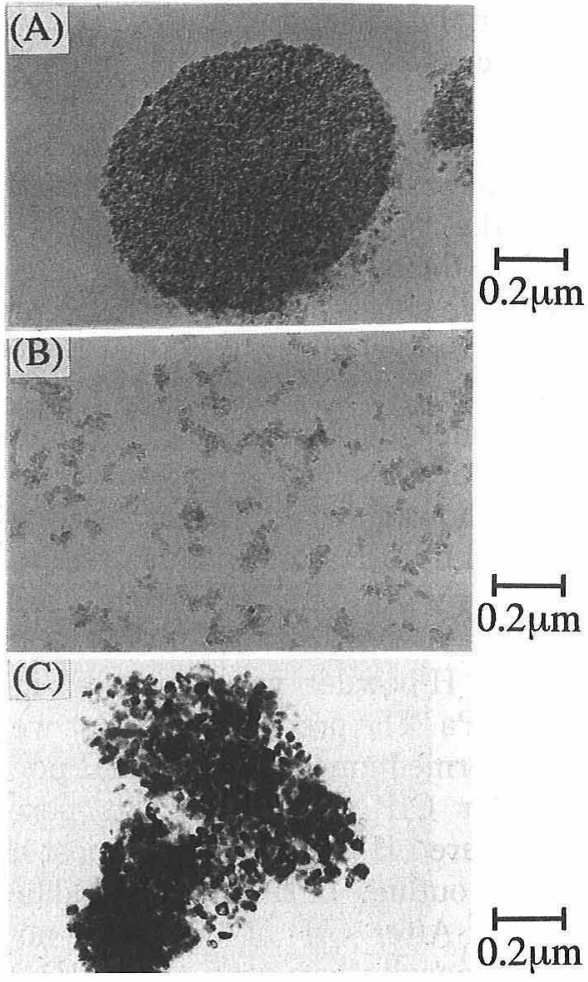

Fig. 1. Internal microstructure of (A) monodispersed titanium dioxide particle hydrothermally treated at $250^{\circ} \mathrm{C}$ for $1 \mathrm{~h}$ and microstructures of (B) primary particles crushed by ultrasonic treatment and of (C) commercial powder.

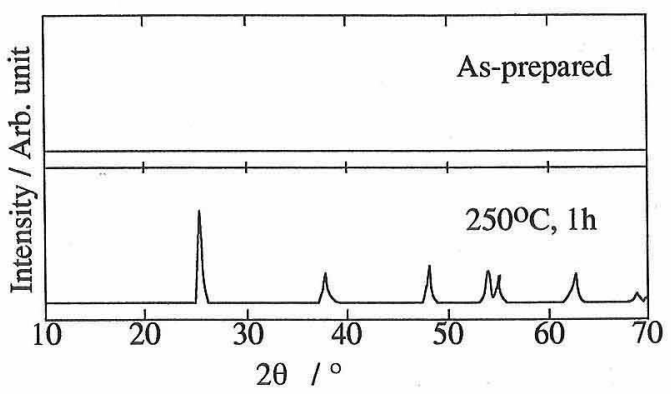

Fig. 2. XRD patterns of as-prepared and hydrothermally treated $\left(250^{\circ} \mathrm{C}, 1 \mathrm{~h}\right)$ monodispersed titanium dioxide particles.

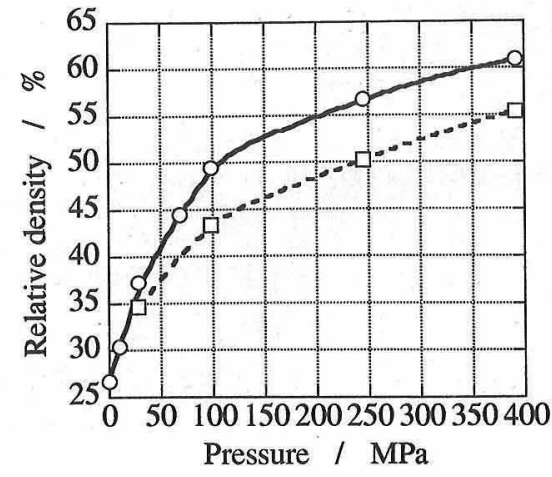

Fig. 3. Change of green density of $(O) \mathrm{H}$-powder and $(\square)$ commercial powder as a function of cold isostatic pressure. 
$\mathrm{H}$-powder in the packing with $392 \mathrm{MPa}$ was $61 \%$ of theoretical density and close to maximum density for a random packing of spherical fine particles $(63.7 \%) .8), 9)$ The relative densities of $\mathrm{H}$-powder are higher than those of the commercial powder although the produced nano-sized particles are smaller than the commercial powder. In some references, relative density of $55 \%$ was also reported for another nano-sized anatase particles $(14-60 \mathrm{~nm})$ formed by filter casting or CIP.6),10),11) It could be obtained more dense green compact using our method without binder.

Figure 4 shows the fracture surfaces of green compacts formed by CIP. The spherical shape of as-prepared powder was kept after the hydrothermal treatment (Fig. 4(A)). However, the clustered spherical structure of $\mathrm{H}$-powder was crushed slightly after $\mathrm{CIP}$ at $29 \mathrm{MPa}$. The produced particles were packed into pores formed among clustered H-powder (Fig. $4(B))$. After CIP at $98 \mathrm{MPa}$, the pores formed among clustered $\mathrm{H}$-powder were almost diminished although the outlines of $\mathrm{H}$-powder could be observed (Fig. 4(C)). After CIP at $392 \mathrm{MPa}$, no shape of clustered H-powder was seen (Fig. 4(D)). In comparison between Figs. 4(A) and (C), the sizes of $\mathrm{H}$ powders were decreased by CIP. This behavior shows that the pores in $\mathrm{H}$-powder were shrunk by CIP.

Figure 5 shows the fracture surface of the green compacts of the commercial powder formed by CIP. The commercial powder agglomerated to form submicron secondary particles (Fig. 5(A)). After CIP at $98 \mathrm{MPa}$, the secondary particles were broken by CIP and the size of the secondary particles decreased (Fig. 5(B)). After CIP at $392 \mathrm{MPa}$, the pores formed among the secondary particles were almost diminished (Fig. 5(C)). However, the size of the secondary particles in Fig. 5(C) seems almost same as that of Fig. 5(B). Hereafter the green compacts of $\mathrm{H}$-powder and the commercial powder
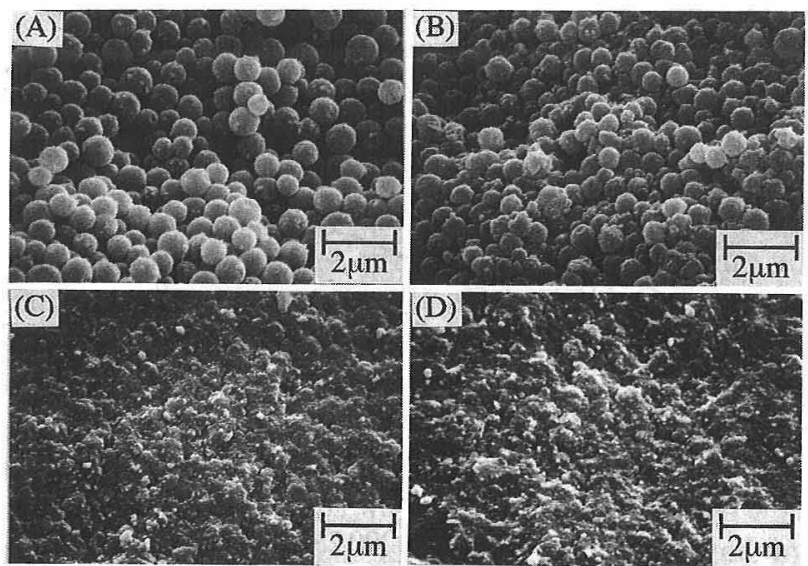

Fig. 4. Fracture surfaces of (A) as-treated body and green bodies formed by CIP with (B) $29 \mathrm{MPa}$, (C) $98 \mathrm{MPa}$ and (D) 392 $\mathrm{MPa}$ of H-powder. formed by CIP with 29,98 and $392 \mathrm{MPa}$ are called the $29 \mathrm{MPa}$ compact, the $98 \mathrm{MPa}$ compact and the $392 \mathrm{MPa}$ compact, respectively.

Figure 6 shows change of the peak positions of pore distributions of green compacts of $\mathrm{H}$-powder and the commercial powder with CIP pressure. As peak position, the values of the right side bottom of a peak were used. The pore distributions of the green compacts of $\mathrm{H}$-powder and the commercial powder
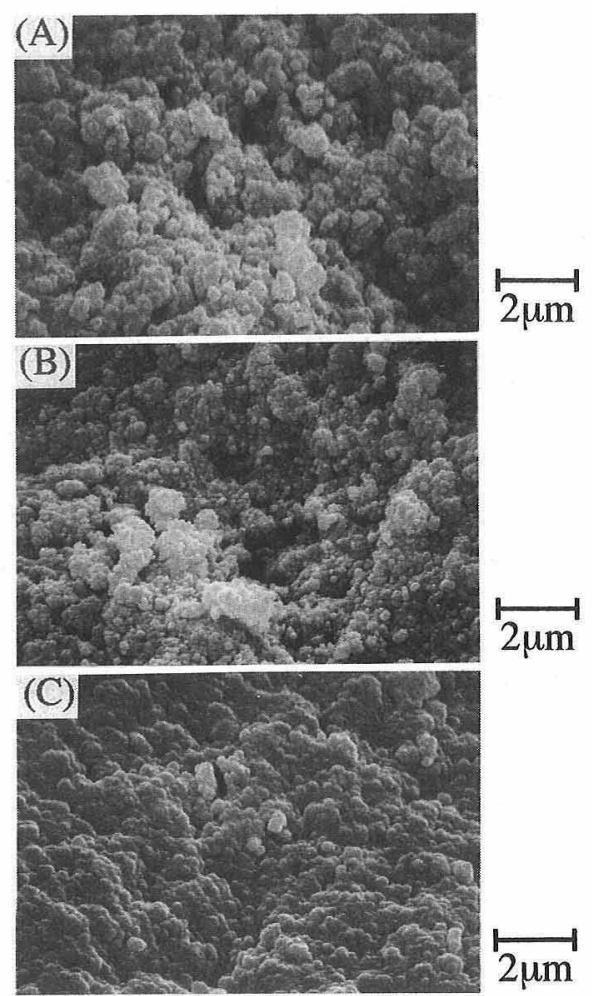

Fig. 5. Fracture surfaces of green bodies of commercial powder formed by CIP with (A) $29 \mathrm{MPa}$, (B) $98 \mathrm{MPa}$ and (C) $392 \mathrm{MPa}$.

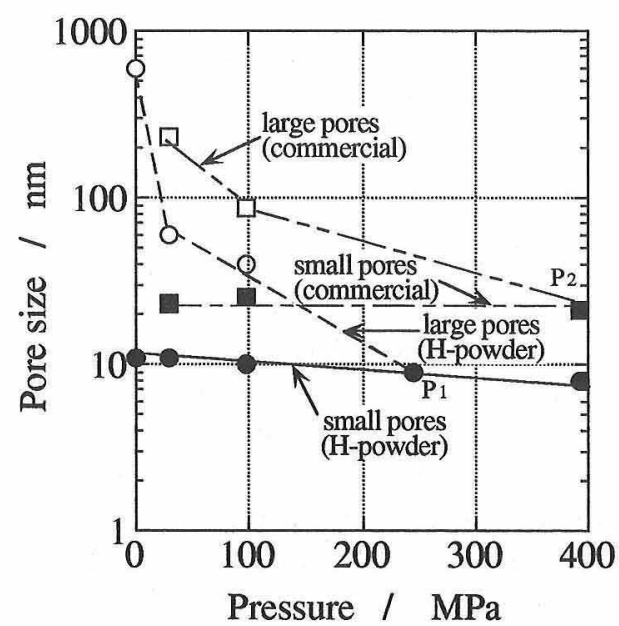

Fig. 6. Change of peak positions of pore size distributions of green bodies as a function of cold isostatic pressure; $(\mathrm{O})$ large pore and ( small pore of $\mathrm{H}$-powder and $(\square)$ large pore and ( $\square$ ) small pore of commercial powder. 
formed with $29 \mathrm{MPa}$ and $98 \mathrm{MPa}$ had two peaks. One is the pores formed among the secondary particles (hereafter called large pore) and the other is the pores formed among the primary nano-sized particles (hereafter called small pore). The large pore of the compacts of $\mathrm{H}$-powder and the commercial powder shrank with an increase in pressure and combined with small pores (points $P_{1}$ and $P_{2}$ ). Since the relative densities of green compacts on $P_{1}$ and $P_{2}$ were same, H-powder can be packed more densely with lower pressure of CIP.

The behavior of small pore were significantly different between $\mathrm{H}$-powder and the commercial powder. The small pore size of the commercial powder was constant with an increase in pressure. However, that of $\mathrm{H}$-powder decreased. This figure indicates that $\mathrm{H}$-powder has higher formability than the commercial powder, although the size of the primary nano-sized particle is smaller. This difference is considered to relate with the agglomeration condition of primary particles. There is also the significant difference between $\mathrm{H}$-powder and the commercial powder in the packing behaviors of the secondary particles (Figs. 4 and 5). The secondary particlcs of the commercial powder were broken by CIP (Fig. 5). However, H-powder was shrunk by CIP (Fig. 4). If the agglomeration of primary particles is not uniform, the secondary particles are broken at weak point (commercial powder). However, if the agglomeration of primary particles is sufficiently weak and nearly equivalent, the particles can be rearranged by CIP (H-powder). The difference of the forming behavior between them is due to uniformity of the structure of secondary particles and to strength of agglomeration of the primary particles. The difference of the disperse ability between $\mathrm{H}$ powder and the commercial powder into isopropanol also supported this explanation (Fig. 1). It may be influenced for high formability of $\mathrm{H}$-powder that the primary particles are single crystals of anatase. ${ }^{7}$ ) Consequently, the structure of $\mathrm{H}$-powder is suitable for dense forming of nano-sized particles.

\subsection{Sintering behavior}

Figure 7 shows the fracture surfaces of the green and sintered bodies $\left(650^{\circ} \mathrm{C}<, 24 \mathrm{~h}\right)$ of the $392 \mathrm{MPa}$ compact of $\mathrm{H}$-powder. The commercial powder could be sintered little below $650^{\circ} \mathrm{C}$. The relative densities of the body sintered at 450 and $650^{\circ} \mathrm{C}$ were $93 \%$ of theoretical density of anatase and $95 \%$ of that of rutile, respectively. Anatase started to change into rutile around $600^{\circ} \mathrm{C}$. The grain size of the body sintered at $450^{\circ} \mathrm{C}$ was almost same as the particle size of the green compact. The grain of the body sintered at $650^{\circ} \mathrm{C}$ grew about ten times. Some references reported that the sintered body of nanosized anatase particles belong to the stage of initial sintering in the sintering temperature below $\left.650^{\circ} \mathrm{C} .{ }^{10)}, 13\right)$ Since Fig. $7(\mathrm{C})$ shows that the body was in the final stage of sintering, the green body of $\mathrm{H}$ -
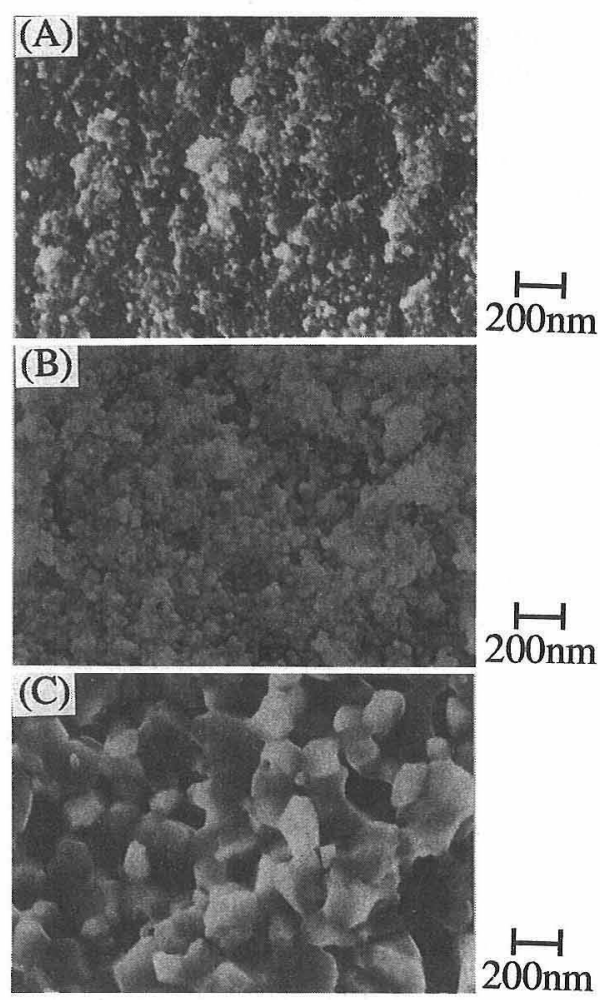

Fig. 7. Fracture surfaces of (A) green compact formed by CIP with $392 \mathrm{MPa}$ of H-powder and of the bodies sintered at (B) $450^{\circ} \mathrm{C}$ and (C) $650^{\circ} \mathrm{C}$ for $24 \mathrm{~h}$.

powder has high sinterability at low temperature. It is considered that the nano-sized particles were packed more densely without binder and there is no inhibition of sintering by binder.

The 29, 98 and $392 \mathrm{MPa}$ compacts of H-powder and the commercial powder were sintered for $24 \mathrm{~h}$. Figure 8 shows change of the density of sintered body with sintering temperature. The sinterability of the $392 \mathrm{MPa}$ compact of the commercial powder is much lower than that of the $29 \mathrm{MPa}$ compact of $\mathrm{H}$ powder. This is due to the effect of the size of their primary particles.

In the $392 \mathrm{MPa}$ compact of $\mathrm{H}$-powder, the relative density reached $98 \%$ of theoretical density at $800^{\circ} \mathrm{C}$ and $99 \%<$ above $900^{\circ} \mathrm{C}$. These densities were much higher than those reported in the Refs. ${ }^{10)-12)}$ In the

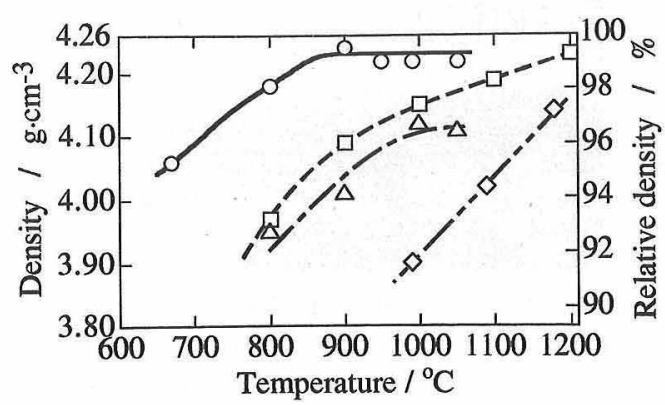

Fig. 8. Change in density of the (O) $392 \mathrm{MPa},(\square) 98 \mathrm{MPa}$, $(\triangle) 29 \mathrm{MPa}$ compact of H-powder and the $(\diamond) 392 \mathrm{MPa}$ compact of commercial powder with sintering temperature for $24 \mathrm{~h}$. 
$98 \mathrm{MPa}$ compact, the degree of the increase of the density below $1000^{\circ} \mathrm{C}$ was almost same as that in the $392 \mathrm{MPa}$ compact. However, the degree of the increase of the density became small above $1000^{\circ} \mathrm{C}$. Finally, the relative density reached $>99 \%$ at $1200^{\circ} \mathrm{C}$. In the $29 \mathrm{MPa}$ compact, the relative density became constant value around $1000^{\circ} \mathrm{C}$. This shows that it is especially important to make a dense uniform and high-sinterable green body in order to sinter a green body consisting of nano-sized anatase particles at a low temperature densely.

Figure 9 shows the microstructures of the polished and the thermally etched surfaces of the $392 \mathrm{MPa}$ compact of $\mathrm{H}$-powder sintered at $900^{\circ} \mathrm{C}$ for $24 \mathrm{~h}$ (Fig. $6(\mathrm{~A})$, etching condition : $880^{\circ} \mathrm{C}, 24 \mathrm{~h}$ ) and of the $29 \mathrm{MPa}$ compact sintered at $1050^{\circ} \mathrm{C}$ for $24 \mathrm{~h}$ (Fig. $6(\mathrm{~B})$, etching condition : $1000^{\circ} \mathrm{C}, 3 \mathrm{~h}$ ). The body in Fig. 6(A) has a fine and uniform microstructure. However, there are some big pores around grain boundaries in Fig. 6(B), although the grains further grow. The lowering of the sinterability of the 29 and $98 \mathrm{MPa}$ compacts of $\mathrm{H}$-powder cause that the large pores could not perfectly be diminished in the compact formed by CIP with 29 and $98 \mathrm{MPa}$.

Figure 10 shows change of the density of the 392 $\mathrm{MPa}$ compact of $\mathrm{H}$-powder by isothermal sintering at 800 and $900^{\circ} \mathrm{C}$. The sintered bodies reached $95 \%$ of theoretical density at $800^{\circ} \mathrm{C}$ and $96 \%$ at $900^{\circ} \mathrm{C}$ within $0.17 \mathrm{~h}$. Therefore, the green body obtained by our method was sintered at a low temperature for short time. This high sinterability also results in the dense formation of green compact of the nano-sized particles without binder and in no inhibition of sintering by binder.
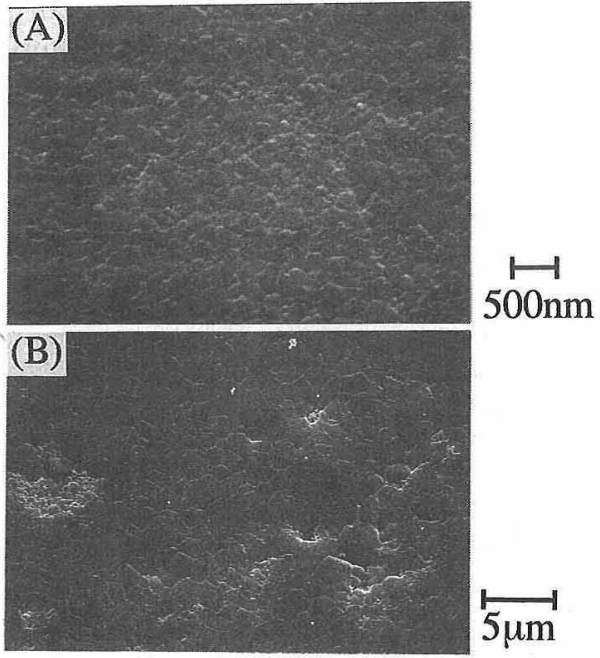

Fig. 9. Microstructures of the polished and thermally etched surfaces of (A) the $392 \mathrm{MPa}$ compact of $\mathrm{H}$-powder sintered at $900^{\circ} \mathrm{C}$ for $24 \mathrm{~h}$ and (B) the $29 \mathrm{MPa}$ compact of $\mathrm{H}$-powder sintered at $1050^{\circ} \mathrm{C}$ for $24 \mathrm{~h}$.

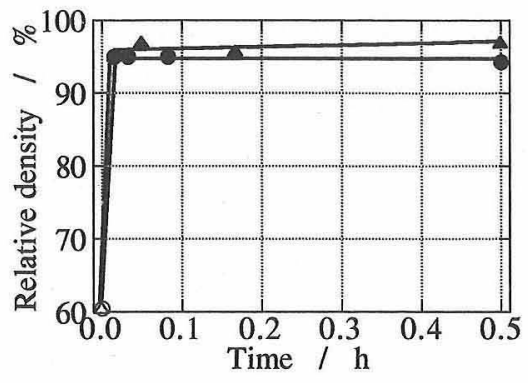

Fig. 10. Isothermal sintering at $(\bigcirc, \bigcirc) 800^{\circ} \mathrm{C}$ and $(\triangle, \Delta)$ $900^{\circ} \mathrm{C}$. The phases are $(O, \triangle)$ anatase and $(O, \Delta)$ rutile.

\section{Conclusions}

The new forming process for the spherically agglomerated nano-sized anatase powder was proposed. The die-pressed compacts of amorphous monodispersed titanium dioxide particles were hydrothermally treated. Many nano-sized anatase were produced in the monodispersed titanium dioxide particles. When as-hydrothermally treated compacts were compressed by CIP under a pressure of $392 \mathrm{MPa}$, the titanium dioxide particles were crushed to give a dense green compact ( $61 \%$ of theoretical density) of nano-sized anatase particles. The high formability of the hydrothermally treated powder results in their structure of uniform and weak agglomeration among nano-sized particles. The green bodies were highly sinterable and gave dense body (99\%) of rutile by sintering at $900^{\circ} \mathrm{C}$ for $24 \mathrm{~h}$.

\section{References}

1) K. Niihara, Electronic Ceramics, 9, 44-48 (1989).

2) K. Niihara, J. Ceram. Soc. Japan, 99, 974-82 (1991).

3) J. S. Reed, "Introduction to the Principles of Ceramic Processing", John Wiley \& Sons, New York (1988) p. 31326

4) E. A. Barringer and H. K. Bowen, J. Am. Ceram. Soc., 65, C199-201 (1982).

5) T. Ikemoto, K. Uematsu, N. Mizutani and M. Kato, YogyoKyokai-Shi, 93, 261-66 (1985).

6) Y. Oguri, R. E. Riman and H. K. Bowen, J. Mater. Sci., 23, 2897-904 (1988).

7) M. Kondo, K. Shinozaki, R. Ooki and N. Mizutani, J. Ceram. Soc. Japan, 102, 742-46 (1994).

8) J. D. Bernal and J. Mason, Nature, 188, 908-11 (1960).

9) P. N. Pusey and W. van Megen, Nature, 320, 340-42 (1986).

10) Y. Suyama and A. Kato, Yogyo-Kyokai-Shi, 89, 140-47 (1981).

11) T. Ota, I. Yamai, J. Takahashi and Y. Tsuchida, NagoyaKogyo-Daigaku-Yogyo-Gijyutsu-Kenkyu-Shisetsu-Nenpo, 15, 21-27 (1988).

12) O. Yamaguchi, H. Omaki, K. Takeoka and K. Shimizu, Funtai-Oyobi-Funmatsu-Yakin, 22, 232-37 (1975).

13) P. G. Vergnon, F. E. Juillet, M. P. Astier and S. J. Teichner, Sci. Ceram., Vol. 5 (1970) pp. 47-62. 